\title{
Qualified with questionable legacies
}

S enator Blackburn appears to be qualified to be a nonaffiliated member of the IACUC at Great Eastern University as defined by Office of Laboratory Animal Welfare Guidance on Qualifications of IACUC Nonscientific and Nonaffiliated Members (NOT-OD-15-109) ${ }^{1}$ and the Animal Welfare Regulations 2.31(b) $\left(\right.$ iii) ${ }^{2}$. However, before appointing Blackburn to the IACUC there are questions that need to be answered: was his opposition in the spirit of the 3Rs (to replace, reduce, or refine the use of animals in research), or was he opposed to use of animals in research for other (personal or professional) reasons?

Prior to being appointed to the IACUC, it would be necessary for the Chair and Blackburn to discuss the IACUC's roles and responsibilities within the institution, as well as Blackburn's responsibilities as an IACUC member. The IACUC is responsible for oversight of the entire animal care and use program and its components, with animal welfare being the utmost priority. The Chair should inform Blackburn that the IACUC's job is to facilitate and support research and the advancement of science while ensuring the highest standard of animal welfare. Blackburn should be made aware that his concerns will be heard but committee decisions are ultimately determined by simple majority; however, he has the right to submit a minority opinion if he strongly opposes the IACUC's decision.

Blackburn should also be made aware of the IACUC's concerns about his past legislative positions and his potential role as a non-affiliated member. Blackburn's past, apparently biased views on the use of animals in biomedical research raises concerns that he could become unreasonably outspoken and potentially obstructive to the functioning of the IACUC.

Lastly, Blackburn should be informed that IACUC members are appointed on term limits which are reviewed annually; that any member can be replaced at that time for reasons that may not be specified; and that any member can resign his or her membership at any time for any manner of reasons.

If the decision is made to appoint Blackburn to the committee, it is imperative that he receive adequate training. Part of this training must include a thorough review of all relevant animal welfare regulations and guidance. Blackburn must be provided with copies of the Guide for the Care and Use of Laboratory Animals, AVMA Guidelines for the Euthanasia of Animals: 2013 Edition, Animal Welfare Act and Regulations, and the IACUC Handbook. We would recommend that this training be provided in-person so that any questions or concerns may be handled appropriately at the time of training. If at all possible, the University should pay for Blackburn to attend a training conference for a more in-depth training experience. Lastly, Blackburn should be reminded that he is representing the community at large, and as such personal feelings must be set aside and the interest of the entire community be taken into account.

While appointing Blackburn to the IACUC at Great Eastern University is a risk, it has the potential to push the IACUC outside their comfort zone, to challenge their thinking and decision making, and to have a positive impact on the institution and Senator Blackburn.

Joseph Matu* and Rachel Murray

Cincinnati Children's Hospital Research Foundation, Cincinnati, Ohio, USA.

*e-mail: joseph.matu@cchmc.org

Published online: 21 May 2019

https://doi.org/10.1038/s41684-019-0309-7

References

1. National Institutes of Health. NOT-OD-15-109: Guidance on Qualifications of IACUC Nonscientific and Nonaffiliated Members. National Institutes of Health Office of Extramural Research. https://grants.nih.gov/grants/guide/notice-files/NOTOD-15-109.html

2. Animal Welfare Act Regulations, 2.31(b)(iii). 